\title{
The potential effects of pregnancy in a patient with idiopathic pulmonary arterial hypertension responding to calcium channel blockade
}

\author{
To the Editor:
}

Pulmonary arterial hypertension (PAH) results in increased pulmonary vascular resistance, right ventricular failure and premature death. Around half of patients with $\mathrm{PAH}$ are diagnosed with idiopathic pulmonary arterial hypertension (IPAH), where no distinct cause is identified $[1,2]$. Patients with IPAH in World Health Organization (WHO) functional classes I-III can be challenged with a vasodilator, such as inhaled nitric oxide, during a right heart catheterisation (RHC) study [3]. "Vasoresponsive" IPAH is universally held to be an excellent prognostic indicator with an entirely different disease course from that in nonresponders [4]. Pregnancy is unequivocally advised against in patients with pulmonary hypertension $(\mathrm{PH})$ as it has been associated with high rates of maternal and fetal death [1,2]; however, there are limited reports in vasoresponders.

A 27-year-old Caucasian woman presented to our specialist pulmonary hypertension centre, having emigrated to the UK. She reported a 6-month history of increasing breathlessness and decreasing exercise tolerance to just a few yards. Previously, she had been fit and active. She was in WHO functional class IV with a history of four syncopal episodes in the previous 6 months. There was no past medical history of note except sertraline taken for anxiety. She denied anorexigenic or illicit drug use. She underwent standard investigations $[1,2]$ that confirmed IPAH (table 1). RHC revealed a mean pulmonary arterial pressure (mPAP) of $52 \mathrm{mmHg}$ with a cardiac output of $3.9 \mathrm{~L} \cdot \mathrm{min}^{-1}$ by thermodilution and pulmonary vascular resistance of 11.5 Wood units. Upon inhalation of $20 \mathrm{ppm} \mathrm{NO}$, mPAP fell to $27 \mathrm{mmHg}$. Her cardiac output was preserved at $4.2 \mathrm{~L} \cdot \mathrm{min}^{-1}$, in keeping with a positive vasoreactive test. Ventilation/ perfusion scanning ruled out chronic thromboembolic $\mathrm{PH}$. Amlodipine was commenced and titrated up to a dose of $20 \mathrm{mg}$ once daily. Anticoagulation with warfarin was commenced. She was strongly advised against pregnancy and encouraged to use dual methods of contraception.

Although functional class IV patients would not routinely be recommended to proceed with oral therapy, 4 months after initiation of therapy, the patient reported resolution of symptoms and was assessed as WHO class I. This was reflected in significant improvements in right heart function and haemodynamics (table 1).

The patient moved back abroad and became pregnant. She decided to proceed with pregnancy whilst continuing calcium channel antagonists but stopped warfarin. The pregnancy was uneventful until 10 days prior to planned, elective caesarean section, when she developed chest pain and was started on a course of low molecular weight heparin. Imaging was not performed at this time to assess for pulmonary embolism. 8 weeks after delivery an elective RHC showed worsening haemodynamics (mPAP $40 \mathrm{mmHg}$ ). Sildenafil (20 mg three times daily) was initiated. Despite this, she functionally deteriorated and a further RHC 3 months later revealed an mPAP of $56 \mathrm{mmHg}$. She was started on bosentan whilst continuing on amlodipine. Warfarin was reinitiated.

The patient relocated back to the UK and was assessed in our centre again. Despite combination therapy, she remained in WHO class III. She reported central chest discomfort upon exertion relieved by rest, and palpitations lasting minutes roughly three times per week, not associated with syncope or presyncope.

@ERSpublications

Counselling for pregnancy in vasoresponder IPAH needs careful consideration http://ow.ly/qunk30fXCRH

Cite this article as: Bostock S, Sheares $\mathrm{K}$, Cannon J, et al. The potential effects of pregnancy in a patient with idiopathic pulmonary arterial hypertension responding to calcium channel blockade. Eur Respir J 2017; 50: 1701141 [https://doi.org/10.1183/13993003.01141-2017]. 
TABLE 1 Case presentation

Date

December 2013
March 2014
December 2014

to September

2015

\section{Events}

Treatment

mPAP $\mathrm{mmHg}$

mPAP with $\mathrm{NO} \mathrm{mmHg}$

CO L. min $^{-1}$

CI L. $\min ^{-1} \cdot \mathrm{m}^{-2}$

PVR Wood units

RV size and function

BNP $\mathrm{pg} \cdot \mathrm{mL}^{-1}$
None

None

52
27
3.9
2.5
11.5
Severely dilated, mildly
impaired systolic function
607

$$
\begin{gathered}
\text { Amlodipine } 20 \mathrm{mg} \\
\text { once daily }
\end{gathered}
$$

28

21

5.1

3.3

3.9

Normal size,

normal systolic function

71
Pregnancy

Amlodipine

$20 \mathrm{mg}$ once daily
Sildenafil $20 \mathrm{mg}$ three times daily, bosentan $125 \mathrm{mg}$ twice daily, amlodipine $20 \mathrm{mg}$ once daily

56

3.8

2.4

12.1

Moderate-severely dilated, severely impaired function 775

mPAP: mean pulmonary arterial pressure; CO: cardiac output; $\mathrm{Cl}$ : cardiac index; PVR: pulmonary vascular resistance; RV: right ventricular; BNP: brain natriuretic peptide.

A 24-h tape was performed and was unremarkable. In view of her deterioration, she underwent a computed tomography pulmonary angiogram. This did not show evidence of thromboembolic disease, coronary compression or any findings that would point to an additional or alternate diagnosis. There were no clinical signs or investigation results to suggest a misclassified initial diagnosis such as connective tissue disease-associated PAH or pulmonary veno-occlusive disease, and the thyroid-stimulating hormone level was normal. At repeat RHC, mPAP was found to be $56 \mathrm{mmHg}$ with no significant response to inhalation of $40 \mathrm{ppm}$ NO (table 1). The patient was transitioned to intravenous prostanoid therapy but unfortunately died suddenly, whilst an inpatient, from a cardiac arrest. Telemonitoring on the ward had not uncovered any arrhythmias prior to her arrest.

Pregnancy is advised against in patients with $\mathrm{PH}[1,2]$. A systematic review of cases of pregnancy in $\mathrm{PH}$ patients between 1978 and 1996 reported a 30\% maternal mortality in pregnancy in patients with IPAH [5]. It is less clear how to counsel vasoresponders, with some equivocation in the literature. A retrospective, multicentre analysis of pregnancy in patients with PAH in the USA between 1999 and 2009 reported two (16.7\%) deaths in a group of 12 women with PAH who chose to continue pregnancy. They reported no deaths (within their follow up interval of 2 months) in the four women in the cohort who had a diagnosis of IPAH [6]. A UK centre conducted a retrospective review of women with $\mathrm{PH}$ who became pregnant and chose to continue pregnancy over a 7-year period. They reported one $(10 \%)$ maternal death associated with 10 pregnancies in nine women during their median follow up interval of 3.2 years [7]. A systematic review of cases over a 10-year period from 1997 to 2007 found an improved mortality rate of $17 \%$ in women with IPAH undergoing pregnancy [8]. The largest registry of pregnancy in women with PAH identified 26 pregnancies across 13 European centres over a 3-year period between 2007 and 2010, and reported a $24 \%$ mortality or transplantation rate in women with IPAH who became pregnant [9]. The subgroup of patients with vasoresponsive IPAH demonstrated no maternal mortality and were all deemed to have had a successful pregnancy. In a year of follow-up post partum, none of this group experienced a clinical deterioration that required a change in therapy. The authors identified that these patients were phenotypically different and had less severe $\mathrm{PH}$ than those who died or required transplantation. They concluded that pregnancy can be successful in this select subgroup of patients with good and aggressive management, but that there are currently insufficient data to generate values to determine when it may be "safe".

Here, we present a case of a patient who responded well to vasodilator therapy, became pregnant and although she progressed through pregnancy with no overt problems, she converted to a nonresponder phenotype and died within 2 years from rapidly progressive disease. We highlight that although there are examples of improved outcomes in vasoresponders, pregnancy may have the potential to dramatically change patient prognosis. We recognise that there are certain vasoresponsive patients who develop a progressive nonresponder phenotype in the absence of pregnancy. Although the temporal relationship of events in this case suggests that pregnancy had a role in the patient's deterioration, there is potential that these events were coincidental. Volume overload in the third trimester may have played a triggering role but we note that the patient continued to deteriorate over the medium term and lost her vasodilatory 
response, and therefore, regardless of the pathophysiological trigger, this carried profound prognostic implications.

This case highlights that in the context of patients with vasoresponsive IPAH, it is critical that the uncertainty around post partum outcomes is discussed. There are few good-quality prospective data in this area and, given the rarity of the vasoresponder subgroup, who only constitute around 5\% of all IPAH, it is unlikely to be available in the future. This case highlights the need to be very clear when counselling patients that, even in the absence of good evidence, there may be a significant chance of death or morbidity during or post-pregnancy.

Samuel Bostock $\oplus^{1}$, Karen Sheares ${ }^{1}$, John Cannon ${ }^{1}$, Dolores Taboada ${ }^{1}$, Joanna Pepke-Zaba ${ }^{1}$ and Mark Toshner ${ }^{1,2}$ ${ }^{1}$ Papworth Hospital NHS Foundation Trust, Cambridge, UK. ${ }^{2}$ University of Cambridge, Cambridge, UK.

Correspondence: Mark Toshner, Papworth Hospital NHS Foundation Trust, Papworth Everard, Cambridge, CB23 3RE, UK. E-mail: mark.toshner@nhs.net

Received: June 082017 | Accepted after revision: Sept 092017

Conflict of interest: Disclosures can be found alongside this article at erj.ersjournals.com

\section{References}

1 Galiè N, Humbert M, Vachiery JL, et al. 2015 ESC/ERS Guidelines for the diagnosis and treatment of pulmonary hypertension: the Joint Task Force for the Diagnosis and Treatment of Pulmonary Hypertension of the European Society of Cardiology (ESC) and the European Respiratory Society (ERS): endorsed by: Association for European Paediatric and Congenital Cardiology (AEPC), International Society for Heart and Lung Transplantation (ISHLT). Eur Heart J 2015; 37: 67-119.

2 Galiè N, Humbert M, Vachiery JL, et al. 2015 ESC/ERS Guidelines for the diagnosis and treatment of pulmonary hypertension. Eur Respir J 2015; 46: 1855-1856.

3 Pepke-Zaba J, Higenbottam TW, Dinh-Xuan AT, et al. Inhaled nitric oxide as a cause of selective pulmonary vasodilation in pulmonary hypertension. Lancet 1992; 388: 1173-1174.

4 Sitbon O, Humbert M, Jais X, et al. Long-term response to calcium channel blockers in idiopathic pulmonary arterial hypertension. Circulation 2005; 111: 3105-3111.

5 Weiss BM, Zemp L, Seifert B, et al. Outcome of pulmonary vascular disease in pregnancy: a systematic overview from 1978 through 1996. J Am Coll Cardiol 1998; 31: 1650-1657.

6 Duarte AG, Thomas S, Safdar Z, et al. Management of pulmonary arterial hypertension during pregnancy: a retrospective, multicenter experience. Chest J 2013; 143: 1330-1336.

7 Kiely DG, Condliffe R, Webster V, et al. Improved survival in pregnancy and pulmonary hypertension using a multiprofessional approach. BJOG 2010; 117: 565-574.

8 Bédard E, Dimopoulous K, Gatzoulis MA. Has there been any progress made on pregnancy outcomes among women with pulmonary arterial hypertension? Eur Heart J 2009; 30: 256-265.

9 Jais X, Olsson KM, Barbera JA, et al. Pregnancy outcomes in pulmonary arterial hypertension in the modern management era. Eur Respir J 2012; 40: 881-885. 